\title{
TTF Derivatives Containing Phosphonic Acid Group As Potent Component for Organic-Inorganic Hybrid
}

\author{
Su-Kyung Lee and Dong-Youn Noh* \\ Department of Chemistry, Seoul Women's University, Seoul 139-774, Korea. *E-mail: dynoh@swu.ac.kr \\ (Received June 16, 2011; Accepted July 27, 2011)
}

Key words: TTF, phosphonic acid, organic-inorganic hybrid, electrochemistry, X-ray crystal structure

\section{INTRODUCTION}

Like ferrocene, tetrathiafulvalene (TTF) is a wellknown electron donor molecule, which exhibits two reversible one-electron redox cycles. ${ }^{1}$ The two-step redox processes are shown in Scheme 1. Utilizing this property, a lot of TTF derivatives have been investigated for the development of organic magnets, sensors, conducting materials, etc. ${ }^{1}$ Various functional compounds such as thiophene, ${ }^{2}$ ferrocene ${ }^{3}$ and azobenzene, ${ }^{4}$ containing the phosphonic acid group have been investigated for the preparation of organic-inorganic hybrid materials exhibiting catalytic activity, non-linear optical properties and photo-induced sensing. TTF amphiphiles with two phosphonic acid moieties were also investigated for the purpose of developing Langmuir-Blodgett magnetic thin films. ${ }^{5}$

In this study, two mono-phosphonic acid derivatives of TTF (compounds $\mathbf{1} \mathbf{b}$ and $\mathbf{2 b}$ in Scheme 2) are synthesized, via the corresponding ethyl phosphonate derivatives, and characterized spectroscopically. Their electrochemical and

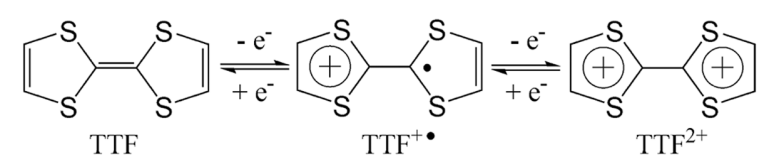

Scheme 1. Two one-electron redox processes of TTF.

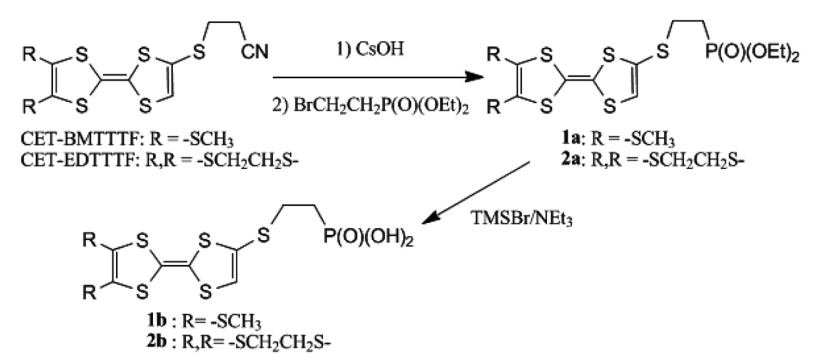

Scheme 2. Synthesis of compounds 1 and 2. structural characterizations were also carried out. This search for a facile way of synthesizing monophosphonic acid derivatives was intended to be the first step in the preparation of zirconium phosphate-based two-dimensional magnetic materials. ${ }^{4}$

\section{EXPERIMENTAL}

The starting materials (CET-BMTTTF ${ }^{5}$ and CET-EDTTTF ${ }^{6}$ ) shown in Scheme 2 were prepared according to the previously reported methods. Cesium hydroxide monohydrate, diethyl 2-bromoethyl phosphonate, triethylamine, bromotrimethylsilane (TMSBr) and HPLC-grade organic solvents were commercially purchased and used as received.

The infrared spectra were recorded by the $\mathrm{KBr}$ pellet method on a Perkin Elmer Spectrum 100 in the range of $4000 \sim 400 \mathrm{~cm}^{-1}$. The ${ }^{1} \mathrm{H}$ NMR spectra were obtained on a Bruker Avance 500 or 300 using $\mathrm{CDCl}_{3}$ as a solvent. Electrochemical studies were carried out at room temperature with a CHI 620A Electrochemical Analyzer (CHI Instrument Inc.) in a $\mathrm{CH}_{2} \mathrm{Cl}_{2}$ solution containing $0.5 \mathrm{mM}$ of the sample and $0.1 \mathrm{Mn}-\mathrm{Bu}_{4} \mathrm{NPF}_{6}$ as the supporting electrolyte, using a Pt-button $(r=1 \mathrm{~mm})$ working electrode, $\mathrm{Ag} /$ $\mathrm{AgCl}$ reference electrode and Pt-wire $(\phi=1 \mathrm{~mm})$ counter electrode at a scan rate of $100 \mathrm{mV} \mathrm{s}^{-1}$. All redox potentials were referenced against the standard $\mathrm{Fc} / \mathrm{Fc}^{+}$redox couple $\left(E_{1 / 2}=+0.504 \mathrm{~V} v s . \mathrm{Ag} / \mathrm{AgCl}\right)$.

Single crystals of compound $\mathbf{2 b}$ suitable for X-ray structure analysis were grown by the slow-evaporation method in $\mathrm{CDCl}_{3}$. The X-ray crystallographic data was collected at 200(2) K on a SMART APEX CCD SYSTEM (Bruker) equipped with graphite-monochromated $\mathrm{Mo}_{\alpha}$ radiation $(\lambda=0.71073 \AA)$. The structure was solved by the direct method and refined by full-matrix least-squares analysis using anisotropic thermal parameters for non-hydrogen atoms with the SHELXTL program. ${ }^{7}$ The crystal data and 
Table 1. Crystal data and structure refinement parameters for 2b $\cdot \mathrm{Et}_{3} \mathrm{~N} \cdot \mathrm{H}_{2} \mathrm{O}$

\begin{tabular}{ll}
\hline E.F & $\mathrm{C}_{16} \mathrm{H}_{26} \mathrm{~N} \mathrm{O}_{4} \mathrm{P} \mathrm{S}_{7}$ \\
F.W & 551.77 \\
Crystal system & Triclinic \\
Space group & $\mathrm{P}-1$ \\
$a(\AA)$ & $9.8469(10)$ \\
$b(\AA)$ & $10.1450(10)$ \\
$c(\AA)$ & $13.0893(14)$ \\
$\alpha\left({ }^{\circ}\right)$ & $79.241(3)$ \\
$\beta\left(^{\circ}\right)$ & $84.258(3)$ \\
$\gamma\left({ }^{\circ}\right)$ & $74.892(2)$ \\
$V\left(\AA^{3}\right)$ & $1238.4(2)$ \\
$Z$ & 2 \\
$D_{\mathrm{c}}\left(\mathrm{Mg} / \mathrm{m}^{3}\right)$ & 1.480 \\
Abs. coeff. $\left(\mathrm{mm}{ }^{-1}\right)$ & 0.724 \\
$F(000)$ & 576 \\
Crystal size $\left(\mathrm{mm}{ }^{3}\right)$ & $0.21 \times 0.17 \times 0.06$ \\
$\theta$ range for data collec. & 1.59 to $28.27^{\circ}$ \\
Index ranges & $-13 \leq h \leq 13,-13 \leq k \leq 13,-17 \leq l \leq 12$ \\
Reflec. Collec. & 9343 \\
Indep. Reflec. & $6073[\mathrm{R}($ int $)=0.0739]$ \\
Completeness to $\theta=28.27^{\circ}$ & $98.8 \%$ \\
Absorption correction & None \\
Refinement method & Full-matrix least-squares on $\mathrm{F}^{2}$ \\
Data/restraints $/$ parameters & $6073 / 0 / 262$ \\
GOF on $\mathrm{F}^{2}$ & 0.770 \\
Final R indices $[\mathrm{I}>2 \sigma(\mathrm{I})]$ & $\mathrm{R} 1=0.0696, \mathrm{wR} 2=0.1220$ \\
Largest diff. peak and hole & 0.632 and $-0.642 \mathrm{e} . \AA-3$ \\
\hline & \\
\hline
\end{tabular}

structure refinement parameters for $\mathbf{2 b} \cdot \mathrm{Et}_{3} \mathrm{~N} \cdot \mathrm{H}_{2} \mathrm{O}$ are listed in Table 1. The detailed crystallographic information is available from the author on request.

Preparation of 1a To an anhydrous DMF solution (20 $\mathrm{mL}$ ) of CET-BMTTTF (1.5 mmol, $572 \mathrm{mg}$ ) degassed for 30 min was added dropwise to a minimum amount of a methanol solution of cesium hydroxide monohydrate $(1.65 \mathrm{mmol}, 277 \mathrm{mg}$ ) over a period of $20 \mathrm{~min}$. During the course of this addition, the color of the solution mixture became dark (red-orange solution). After stirring this mixture for an additional $30 \mathrm{~min}$, diethyl 2-bromoethyl phosphonate $(1.4 \mathrm{mmol}, 0.25 \mathrm{~mL})$ was added. The resulting dark brown mixture was stirred for $3 \mathrm{~h}$. The white precipitate was filtered off, and the solvent was removed in vacuo. The product was separated by column chromatography $\left(\mathrm{SiO}_{2}\right.$, acetone: diethyl ether=3:2) as orange-brown oil. Yield: $62 \%$ (425 mg), ${ }^{1} \mathrm{H} \mathrm{NMR}\left(300 \mathrm{MHz}, \mathrm{CDCl}_{3}, \mathrm{ppm}\right)$ $6.44(1 \mathrm{H}, \mathrm{CH}, \mathrm{s}), 4.15-4.06\left(4 \mathrm{H}, \mathrm{CH}_{2}, \mathrm{~m}\right), 2.99-2.90(2 \mathrm{H}$, $\left.\mathrm{SCH}_{2}, \mathrm{~m}\right) 2.43\left(6 \mathrm{H}, \mathrm{SCH}_{3}, \mathrm{~s}\right), 2.17-2.02\left(2 \mathrm{H}, \mathrm{CH}_{2} \mathrm{P}, \mathrm{m}\right)$, 1.36-132 $\left(6 \mathrm{H}, \mathrm{CH}_{3}, \mathrm{t}\right)$, FT-IR $\left(\mathrm{KBr}, \mathrm{cm}^{-1}\right) 2982,2921\left(-\mathrm{CH}_{3}\right.$,
$\left.-\mathrm{CH}_{2} \mathrm{CH}_{2}-\right), 1477,1424,1391,1368\left(-\mathrm{CH}_{2} \mathrm{~S}-\right), 1243(\mathrm{P}=\mathrm{O})$, 1054, 1027, 964 (P-OEt), 888 (asym S-C-S str), 784, 771 $(\mathrm{P}-\mathrm{C}), 528\left(\mathrm{R}(\mathrm{RO})_{2} \mathrm{P}=\mathrm{O}\right)$.

Preparation of 2a Compound 2a was prepared by the same method as that employed for compound 1a using DMF ( $25 \mathrm{~mL}$ ), CET-EDTTTF ( $0.70 \mathrm{mmol}, 265 \mathrm{mg}$ ), $\mathrm{CsOH}$ (0.77 mmol, $129 \mathrm{mg}$ ), and diethyl 2-bromoethyl phosphonate $(0.77 \mathrm{mmol}, 0.14 \mathrm{~mL})$. Yield: $92 \%(318 \mathrm{mg}),{ }^{1} \mathrm{H}$ NMR (300 MHz, $\left.\mathrm{CDCl}_{3}, \mathrm{ppm}\right) 6.44(1 \mathrm{H}, \mathrm{CH}, \mathrm{s}), 4.17-$ $4.06\left(4 \mathrm{H}, \mathrm{CH}_{2}, \mathrm{~m}\right), 3.26\left(4 \mathrm{H}, \mathrm{CH}_{2} \mathrm{CH}_{2}, \mathrm{~s}\right) 2.98-2.93(2 \mathrm{H}$, $\left.\mathrm{SCH}_{2}, \mathrm{~m}\right), 2.13-2.02\left(2 \mathrm{H}, \mathrm{CH}_{2} \mathrm{P}, \mathrm{m}\right), 1.36-131\left(6 \mathrm{H}, \mathrm{CH}_{3}\right.$, t), FT-IR $\left(\mathrm{KBr}, \mathrm{cm}^{-1}\right) 2980,2926,2853\left(-\mathrm{CH}_{2} \mathrm{CH}_{2}-\right), 1716$ $(\mathrm{C}=\mathrm{C}), 1463,1442,1411,1391,1367\left(-\mathrm{CH}_{2} \mathrm{~S}-\right), 1241(\mathrm{P}=\mathrm{O})$, 1056, 1028, 961 (P-OEt), 886 (asym S-C-S str), 803, 772 (P-C).

Preparation of $\mathbf{1 b}$ and $\mathbf{2 b}$ Triethylamine $(0.58 \mathrm{~mL}, 28$ $e q$.) was added to a dichloromethane solution $(4 \mathrm{~mL})$ of $\mathbf{1 b}$ $(0.15 \mathrm{mmol}, 74 \mathrm{mg})$ or $\mathbf{2 b}(0.15 \mathrm{mmol}, 73 \mathrm{mg})$, to which $\mathrm{TMSBr}(0.56 \mathrm{~mL}, 28 \mathrm{eq}$.) was slowly added from a syringe. During this addition, a white precipitate became evident in the flask. After stirring for $2 \mathrm{~h}$, the solution was concentrated in vacuo and methanol $(4 \mathrm{~mL})$ was added to the resulting residue followed by additional stirring for $4 \mathrm{~h}$. The product was concentrated in vacuo, dissolved in dichloromethane, and extracted by distilled de-ionized water. The extraction procedure using dichloromethane resulted in the product being obtained as orange brown oil. Single crystals of $\mathbf{2 b}$ were obtained in $\mathrm{CDCl}_{3}$.

1b: Yield: 54\%, ${ }^{1} \mathrm{H}$ NMR (500 MHz, $\mathrm{CDCl}_{3}$, ppm) 10.72 $(2 \mathrm{H}, \mathrm{OH}, \mathrm{br}), 6.26(1 \mathrm{H}, \mathrm{CH}, \mathrm{s}), 3.11\left(2 \mathrm{H}, \mathrm{SCH}_{2}, \mathrm{br}\right) 2.44$ $\left(6 \mathrm{H}, \mathrm{SCH}_{3}, \mathrm{~s}\right), 2.02\left(2 \mathrm{H}, \mathrm{CH}_{2} \mathrm{P}, \mathrm{br}\right)$, FT-IR $\left(\mathrm{KBr}, \mathrm{cm}^{-1}\right)$ 2972, $2919\left(-\mathrm{CH}_{3},-\mathrm{CH}_{2} \mathrm{CH}_{2}-\right), 2687(\mathrm{P}-\mathrm{OH}), 1735(\mathrm{C}=\mathrm{C})$, 1456, $1428\left(-\mathrm{CH}_{2} \mathrm{~S}-\right), 1291(\mathrm{P}=\mathrm{O}), 1159(\mathrm{P}-\mathrm{O}-\mathrm{H}), 1047$, $935\left((\mathrm{OH})_{2} \mathrm{P}=\mathrm{O}\right), 804$ (asym S-C-S str), 771 (P-C).

2b: Yield: 77\%, ${ }^{1} \mathrm{H}$ NMR (500 MHz, $\left.\mathrm{CDCl}_{3}, \mathrm{ppm}\right) 11.84$ (2H, OH, br), $6.36(1 \mathrm{H}, \mathrm{CH}, \mathrm{s}), 3.29\left(4 \mathrm{H}, \mathrm{CH}_{2} \mathrm{CH}_{2}, \mathrm{~s}\right)$, 3.02-2.99 (2H, $\left.\mathrm{SCH}_{2}, \mathrm{~m}\right), 1.98-1.91\left(2 \mathrm{H}, \mathrm{CH}_{2} \mathrm{P}, \mathrm{m}\right)$, FT-IR $\left(\mathrm{KBr}, \mathrm{cm}^{-1}\right)$ 2977, $2928\left(-\mathrm{CH}_{2} \mathrm{CH}_{2}-\right), 2678(\mathrm{P}-\mathrm{OH}), 1488$, 1452, 1422, $1392\left(-\mathrm{CH}_{2} \mathrm{~S}-\right), 1287(\mathrm{P}=\mathrm{O}), 1126(\mathrm{P}-\mathrm{O}-\mathrm{H})$, $1073,1061,939,920,893\left((\mathrm{OH})_{2} \mathrm{P}=\mathrm{O}\right), 835,804$ (asym S-C-S str), 771 (P-C).

\section{RESULTS AND DISCUSSION}

The TTF derivatives with ethylcyanide groups (CETBMTTTF and CET-EDTTTF) synthesized by the phosphite-based cross-coupling reaction ${ }^{6}$ were transformed into the corresponding diethyl phosphonate derivatives (1a and 2a, respectively). Subsequently, their treatment with 


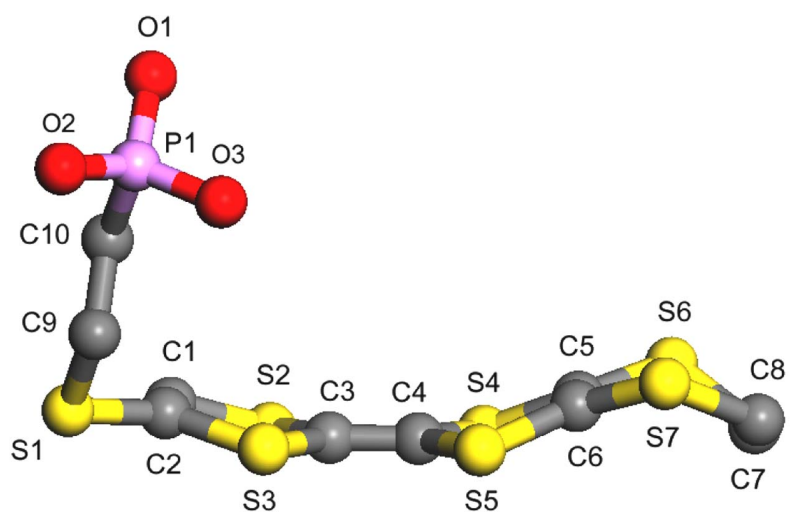

Fig. 1. Molecular structure of $\mathbf{2 b}$ with numbering scheme. The hydrogen atoms and solvated molecules are omitted for clarity. Selected bond lengths $(\AA)$ and angles $\left(^{\circ}\right)$ : C1-C2 1.323(9), C3C4 1.351(8), C5-C6 1.340(8), C7-C8 1.415(10), C9-C10 1.511(9), C10-P1 1.809(7), P1-O1 1.493(5), P1-O2 1.507(5), P1O3 1.552(5), C4-C3-S2 123.3(5), C4-C3-S3 122.3(5), S2-C3-S3 114.4(4), C3-C4-S5 124.2(5), C3-C4-S4 121.9(5), S5-C4-S4 113.9(4), O1-P1-O2 115.5(3), O1-P1-O3 110.1(3), O2-P1-O3 $109.9(3)$.

$\mathrm{TMSBr}$ in the presence of triethylamine afforded the phosphonic acid derivatives (1) and $\mathbf{2 b}$, respectively). The isolated compounds were identified with ${ }^{1} \mathrm{H}$ NMR and FT-IR spectroscopies.

Single crystals of $\mathbf{2} \mathbf{b}$ were grown and its crystal structure was analyzed by the X-ray diffraction method. The molecular structure of $\mathbf{2 b}$ (Fig. 1) shows that the TTF moi- ety is slightly folded-up with the peripheral ethylene moiety folded downwards and the ethylphosphonic acid moiety is approximately vertical to the EDTTTF plane. The intramolecular bond lengths and angles fell in the range of their averaged values. ${ }^{8}$ Only one intermolecular interaction shorter than the sum of their van der Waals $\operatorname{radii}(3.70 \AA)^{8}$ is observed, viz. S4...S5* $\left(3.583 \AA ;{ }^{*}-\mathrm{x}+1\right.$, $-\mathrm{y}+1,-\mathrm{z})$.

Cyclic voltammetry (CV) and differential pulse voltammetry (DPV) measurements of $\mathbf{1 b}$ and $\mathbf{2 b}$ were performed and their parameters are listed in Table 2. The two compounds show the same redox behavior, exhibiting two reversible redox-cycles (Fig. 2) at almost the same potentials. These cycles are undoubtedly attributable to the two redox-steps of the TTF moiety. The half-wave potentials of the EDTTTF moiety in $2 \mathbf{b}\left(E_{1 / 2}^{1}=0.610 \mathrm{~V}\right.$ and $E_{1 / 2}^{2}=$ $1.035 \mathrm{~V})$ are slightly more anodic than those of BMTTTF $(0.608 \mathrm{~V}$ and $1.000 \mathrm{~V})$, possibly due to the additional peripheral 6-membered ring.

In summary, two TTF derivatives with the mono-phosphonic acid group, which can be utilized as a potent component for functional organic-inorganic hybrids such as zirconium phosphate, were successfully synthesized in a facile way of reacting the corresponding ethyl phosphonate with bromotrimethylsilane (TMSBr) and triethylamine, and characterized by ${ }^{1} \mathrm{H}$ NMR and FT-IR spectroscopies. Their electrochemical properties also indicate the pres-

Table 2. The CV parameters (in V) of $\mathbf{1 b}$ and $\mathbf{2} \mathbf{b}{ }^{a}$

\begin{tabular}{ccccccc}
\hline Compound & $E_{\mathrm{pa}}^{1}$ & $E_{\mathrm{pa}}^{2}$ & $E_{\mathrm{pc}}^{1}$ & $E_{\mathrm{pc}}^{2}$ & $E_{1 / 2}^{{ }^{b}}$ & $E^{2}{ }_{1 / 2}^{b}$ \\
\hline $\mathbf{1 b}$ & 0.665 & 1.058 & 0.550 & 0.941 & 0.608 & 1.000 \\
$\mathbf{2 b}$ & 0.674 & 1.100 & 0.545 & 0.970 & 0.610 & 1.035 \\
\hline
\end{tabular}

${ }^{a}$ The samples are dissolved in $\mathrm{CH}_{2} \mathrm{Cl}_{2}$ containing $0.1 \mathrm{M}$ TBA.PF 6 electrolyte and analyzed using a scan rate of $0.1 \mathrm{~V} / \mathrm{s}$, Pt-disk working electrode, $\mathrm{Pt}$-wire counter electrode, and $\mathrm{Ag} / \mathrm{AgCl}$ ref. electrode. All potential values are referenced to the $\mathrm{Fc} / \mathrm{Fc}^{+}$couple $\left(E_{1 / 2}=+0.504 \mathrm{~V}\right)$.

${ }^{b} E_{1 / 2}=\left(E_{\mathrm{pa}}+E_{\mathrm{pc}}\right) / 2$
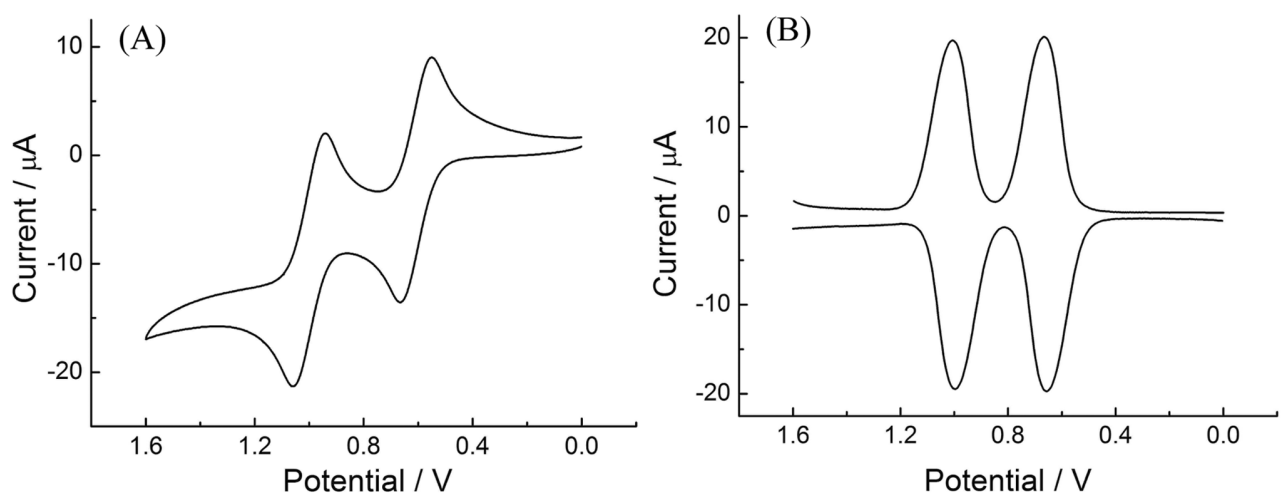

Fig. 2. The $\mathrm{CV}$ (A) and its DPV (B) of $\mathbf{1 b}$ measured in $\mathrm{CH}_{2} \mathrm{Cl}_{2}\left(\mathrm{Fc} / \mathrm{Fc}^{+}=0.504 \mathrm{~V}\right.$ vs. $\left.\mathrm{Ag} / \mathrm{AgCl}\right)$. Compound $\mathbf{2 b}$ shows identical patterns in its CV and DPV to those of $\mathbf{1 b}$. 
ence of the TTF moiety in the compounds. One of the compounds was also analyzed by the X-ray diffraction method.

Acknowledgments. This work was supported by a research grant from Seoul Women's University (2010).

\section{REFERENCES}

1. (a) Yamada, J.; Sugimoto, T. TTF Chemistry: Fundamentals and Applications of Tetrathiafulvalene; Kodansha \& Springer: Tokyo, 2004. (b) Narita, M.; Pittman, C. U. Synthesis 1976, 489. (c) Keief, A. Tetrahedron 1986, 42, 1209. (d) Williams, J. M.; Ferraro, J. R.; Thorn, R. J.; Carlson, K. D.; Geiser, U.; Wang, H. H.; Kini, A. M.;
Whangbo, M.-H. Organic Superconductors (including Fullerenes): Synthesis, Structure, Properties and Theory; Prentice Hall: Englewood Cliffs, NJ, 1992.

2. Gerbier, P.; Guérin, C.; Henner, B.; Unal, J. R. J. Mater. Chem. 1999, 9, 2559.

3. Frantz, R.; Carré, F.; Durand, J. O.; Lanneau, G. F. New J. Chem. 2001, 25, 188.

4. Wu, A.; Talham, D. R. Langmuir 2000, 16, 7449.

5. Petruska, M. A.; Watson, B. C.; Meisel, M. W.; Talham, D. R. Chem. Mater. 2002, 14, 2011.

6. Kwon, S. Y.; Cho, J. H.; Lee, H. I.; Lee, U.; Noh, D. Y. Inorg. Chem. Commun. 2005, 8, 510.

7. Sheldrick, G. M. SHELXTL, version 5, Bruker AXS: Madison, Wisconsin, 1995.

8. Bondi, A. J. Phys. Chem. 1964, 69, 441. 